\title{
Quantitative Relationships between Weathering Indices and Physical Properties: A Case Study of Monzonitic Granite Weathering Profile in Qingdao Area, China
}

\author{
SHI- KuO LU*, XUE-TAO WANG, SHOU-QIAN ZhanG, \\ XIN-ZENG FAN \\ School of Geosciences, China University of Petroleum, \\ Qingdao 266580, China(*Correspondence: \\ Shikuolu@outlook.com)
}

The chemical, mineralogical and physical properties of rocks alter apparently in the weathering. Most of the existing researches on rock weathering have been focused on the rocks' geochemical alteration. Contrarily, it is not known well about the change pattern of physical properties of weathered rocks. Especially, there are few reports about the quantitative relationship between the chemical weathering intensity and rocks' physical properties. Here we select a weathering profile of monzonitic granite in Qingdao area, eastern China. Based on analyzing the mineralogical and chemical alteration characteristics by microscope, XRF and XRD, we pay more attention to exploring the relationship between the chemical wreathing indices and a series of physical parameters of monzonitic granite, such as density, $\mathrm{P}$-wave velocity, $\mathrm{S}$-wave velocity, modulus of elasticity and porosity etc., and find some interesting results. Firstly, the mineralogical and chemical characteristics of monzonitic granite change regularly with the depth of weathering profile. The rocks' chemical weathering characteristics can be well described by weathering potential indices CIA, WIC and WIG. Moreover, as far as the relationship between the rocks' chemical weathering indices and their physical properties is concerned, it is found that the velocity of $\mathrm{P}$-wave and $\mathrm{S}$-wave, apparent density and modulus of elasticity of monzonitic granite all decrease with the depth of the weathering profile becoming shallow, whereas rocks' porosity shows an opposite trend. Being compared with the other two weathering indices WIC and WIG, the index CIA shows a better linear relationship with density and porosity of monzonitic granite with the coefficient of determination $\mathrm{R}^{2}$ being greater than 0.8 , suggesting that the weathering potential index CIA could be used to predict some physical properties of weathered monzonitic granite so as to be able to provide data references for solving the relative geological problems. This research is funded by National Natural Science Foundation of China(41472106). 